\title{
NO MUNDO DOS BICHOS: UMA METÁFORA SOBRE OS DIZERES ${ }^{1}$
}

BARBOSA, Maria do Carmo Rodrigues ${ }^{2}$

Recebido em: 2009-05-07

Aprovado em: 2009-08-03

ISSUE DOI: $10.3738 / 1982.2278 .171$

RESUMO: Esse artigo busca, a partir de conceitos da Análise de Discurso da linha francesa de Michel Pêcheux, e da narrativa de "A Revolução dos Bichos" de George Orwell, refletir sobre a topologia do hipertexto. Além do mais, faz uma reflexão sobre o sujeito da linguagem e como ele se inscreve socialmente e inscreve sentidos na rede. O discurso eletrônico propicia ao sujeito da linguagem os efeitos de sentidos diferentes daqueles sujeitos da rede. No discurso eletrônico, há dois percursos: no primeiro, o sujeito tem a oportunidade de entrar em uma página onde tudo já está pronto ou, no segundo, o sujeito que quer fundar, escrever.

Palavras-chaves: Discurso. Sujeito. Memória. Arquivo. Hipertexto.

\section{IN ANIMAL'S WORLD - A METAPHOR ABOUT SAYINGS}

SUMMARY: This article search, as of the concepts of the Discourse Analysis from the Michel Pêcheux's French line, and as of the narrative "Animal Farm", of George Orwell, reflect about the hypertext's topology. Moreover, it makes a reflection about the language's subject and the way it socially inscribe and the way it inscribe meanings in the network. The electronic discourse propitiate to the language's subject the different meaning's effects from the network's subjects. In the electronic discourse there are two courses: in the first, the subject has the opportunity of entry in a page where everything is already or, in the second, the subject who wants to institute, write.

Keywords: Discourse. Subject. Memory. Archieve. Hypertext.

\section{INTRODUÇÃO}

\author{
OS SETE MANDAMENTOS \\ 1. Qualquer coisa que ande sobre duas pernas é inimigo. \\ 2. O que ande sobre quatro pernas, ou tenha asas, é amigo. \\ 3. Nenhum animal usará roupa. \\ 4. Nenhum animal dormirá em cama. \\ 5. Nenhum animal beberá álcool. \\ 6. Nenhum animal matará outro animal. \\ 7. Todos os animais são iguais (ORWELL, 2007).
}

\footnotetext{
1 Este artigo é parte integrante da monografia apresentada à Prof. Dra. Lucília Maria Sousa Romão, Departamento de Psicologia e Educação da Faculdade de Filosofia, Ciências e Letras de Ribeirão Preto - USP.

${ }^{2}$ Mestre em Educação. Docente na FE/FFCL.
} 
“[...] A metáfora é uma espécie de repetição vertical, em que a própria memória esburaca-se, perfura-se antes de desdobrar-se em paráfrase [...] (PÊCHEUX, 1997)."

Nesse artigo, pretende-se refletir sobre o discurso eletrônico que propicia ao sujeito os efeitos de sentidos diferentes daqueles sujeitos e sentidos da narrativa escrita.

Discute-se a partir da narrativa A Revolução dos Bichos, de George Orwell, a navegação como a possibilidade de os sujeitos inscreverem discursivamente suas fantasias, portanto recorremos à textualidade eletrônica com o objetivo de me ajudar a interpretar o que acontece na Granja do Solar.

\section{GRANJA DO SOLAR: MAIS TARDE GRANJA DOS BICHOS}

A narrativa mostra que, cansados da exploração a que são submetidos pelos humanos, os animais da Granja do Solar, mais tarde Granja dos Bichos, rebelam-se contra seus donos e tomam posse da fazenda, com o objetivo de instituir um sistema cooperativo e igualitário, sob o slogan Quatro pernas bom, duas pernas ruim. Esse slogan condensava os Sete Mandamentos que, para Bola-de-Neve, era o princípio essencial do Animalismo.

Porém não demora muito para que alguns bichos, os porcos, voltem a usufruir de privilégios, reinstituindo aos poucos um regime de opressão, agora inspirado no lema "Todos os bichos são iguais, mas alguns bichos são mais iguais do que outros". A história da insurreição libertária dos animais é reescrita de modo a justificar a nova tirania, e os dissidentes desaparecem ou são silenciados à força.

Na verdade A Revolução dos Bichos, em suas metáforas, revela uma aversão a toda espécie de autoritarismo, seja ele familiar, comunitário, estatal ou capitalista. É um livro fascinante. O discurso de Orwell tem tudo a ver com os dias atuais, pois fala sobre abusos de poder, propagandas enganosas e, cada vez mais, a desigualdade social. O conto é impregnado de uma teia de possibilidade de efeitos.

Esse artigo apresenta alguns recortes e tenta "costurá-los" à noção de hipertexto; discurso; memória; textualidade eletrônica e arquivo.

\section{Recorte - 1}

"Camaradas", disse ele, "eis aí um ponto que precisa ser esclarecido. As criaturas rebeldes, tais como os ratos e os coelhos, serão nosso amigos ou nosso inimigos? 
Coloquemos o assunto em votação. Apresento à assembléia a seguinte questão: são os ratos camaradas?"

A votação foi realizada imediatamente, e concluiu-se, por esmagadora maioria, que os ratos eram camaradas. [...] O Major prosseguiu:

Pouco mais tenho a dizer. Repito apenas: lembrai-vos sempre do vosso dever de inimizade para com o Homem e todos os desígnios. O que quer que ande sobre duas pernas é inimigo; o que quer que ande sobre quatro pernas ou tenha asas, é amigo. Lembrai-vos também de que na luta contra o Homem não devemos ser como ele. Mesmo quando o tenhais derrotado, evitai-lhe os vícios (ORWELL, 2007, p. 14-15).

Esses três parágrafos revelam uma expectativa e esperança de que os bichos poderiam ser amigos. Porém, em um trabalho de leitura e interpretação, deve-se considerar que esse conto, produzido por Orwell, tentou mostrar uma época específica (Revolução Russa -1917). Sua obra pode e deve ser vista como uma alegoria a qualquer revolução em que os mais fracos tomam o poder e, em seguida, são por ele corrompidos.

Nesse fragmento se instaura um discurso político:

O discurso político é produzido pelo falante, seja o discurso que nasce de uma fonte em um momento histórico definido, por exemplo, o discurso produzido pela formação naquela conjuntura etc; ao impor uma série sucessiva de coerções sobre os materiais que os tornam homogêneos (COURTINE, 2006, p. 66).

\section{O HIPERTEXTO: MEDIADOR DE INFORMAÇÃO}

Hipertexto é um médium de informação que existe apenas on-line num computador. É uma estrutura composta de blocos de textos conectado por links eletrônicos que oferecem diferentes caminhos para os usuários. O hipertexto providencia um meio de arranjar a informação numa maneira não-linear tendo o computador como o automatizador das ligações de uma peça de informação com outra (SNYDER, 1998, p. 126).

O hipertexto é um documento que pode ser lido do início para o final ou do final para o início. Ele é móvel, maleável, aberto. O leitor pode escolher aquilo que lhe interessa. Pode deslocar, recortar, estender, recompor as unidades textuais (CHARTIER, 2002).

O hipertexto é um conjunto de nós ligados por conexões, não possui uma estrutura fixa como página, prólogo, capítulo, sessão, prefácio, conclusão, mas na verdade é um labirinto onde muitas vezes nos perdemos, pois, às vezes, a página é inspirada ou não foi encontrada.

No texto impresso é diferente, pois podemos fechar o livro e no outro dia iniciarmos a nossa leitura no ponto em que paramos. No texto eletrônico, é necessário entrar na rede, conectar, localizar o site, abrir as páginas até chegar onde estávamos e, muitas vezes, não encontramos mais aquela página, porque ao invés de indicar o site, vamos pela busca ou pesquisa que poderá nos indicar um outro site que traz o mesmo assunto. Para Romão (2005), 
a navegação on-line permite que um trajeto seja interrompido e modificado de direção a qualquer clique, ampliando as chances de o leitor escapar por meio de outras páginas eletrônicas e por entre as frestas da imensidão desta teia de conexões.

\section{O DISCURSO E AS CLIVAGENS SUBTERRÂNEAS}

O discurso é o objeto teórico da Análise do Discurso (objeto histórico - ideológico), que se produz socialmente através da materialidade específica, a língua. É uma prática social cuja regularidade só pode ser apreendida a partir da análise dos processos de sua produção, não dos seus produtos. O discurso é dispersão de textos e a possibilidade de entender o discurso como prática deriva da própria concepção de linguagem marcada pelo social e histórico com a qual a Análise de Discurso trabalha.

No discurso eletrônico, deparamo-nos com dois percursos: no primeiro, o sujeito tem a possibilidade de entrar em uma página onde tudo já está pronto ou, no segundo, o sujeito que quer fundar, escrever.

Segundo Romão (2006),

Essa divisão, entre aqueles que estão autorizados a ler e escrever em seu nome e os que não podem ocupar essa posição aparece re-configurada no livro eletrônico. Há também, em relação à internet, esses lugares marcados imaginariamente que criam espaços para instalar sua voz, seus ditos e suas leituras, em blogs, listas de discussão, homepages, páginas eletrônicas, etc., e outros apenas acessam-nos; em que alguns podem entrar em determinados arquivos eletronicamente organizados, porque são pagantes, e outros ficam do lado de fora, visto que não possuem cartão nem crédito.

Aplicando essa teoria escolhemos dois fragmentos do livro impresso de A Revolução dos Bichos e tentaremos esboçar uma pequena análise.

\section{Recorte - 2}

Bola-de-Neve achara, no depósito, uma velha toalha verde de mesa, e pintara no centro, em branco, um chifre e um casco. Essa era a bandeira que subia ao topo do mastro no pátio da casa todos os domingos pela manhã. O verde da bandeira, explicava Bola-de-Neve, representava os verdes campos da Inglaterra, ao passo que o chifre e os cascos simbolizavam a futura República dos Bichos, cujo advento teria lugar no dia em que o gênero humano, enfim, desaparecesse. Após o hasteamento da bandeira, iam todos ao grande celeiro para assistir a uma assembléia-geral conhecida como a Reunião (ORWELL, 2007, p. 30).

Bola-de-Neve, porco muito inteligente, talvez o mais inteligente, apregoava a igualdade social para todos, e mesmo sendo administrador da Granja dos Bichos, não se aproveitava dessa posição. Substitui o velho Major, porco que idealizou a Revolução e era o 
mais inteligente dos animais e líder até sua morte. Porém, só após a Morte de Major, seus ideais igualitários foram aplicados, surgindo Bola-de-Neve e Napoleão, os dois porcos que comandarão a revolução contra o Sr. Jones. Napoleão, partidário do totalitarismo, foi criado para representar Stálin. Bola-de-Neve era o Trotski, transformando-se, à custa de muita propaganda, no inimigo da revolução.

Para a Análise do Discurso, os objetos simbólicos produzem sentidos, e, na bandeira criada por Bola-de-Neve, o chifre e o casco pintados no centro eram os símbolos do Animalismo, fazendo referências ao Comunismo.

O discurso de Bola-de-Neve, durante todo o livro, é um discurso histórico e ideológico, entusiasma-se com a possibilidade de uma revolução sem fronteiras. Sonha em tornar a fazenda independentemente dos homens e, ao mesmo tempo, pensa em levar a rebelião a outras fazendas da Inglaterra e países vizinhos.

\section{Recorte -3}

Os porcos já liam e escreviam muito bem. Os cães aprenderam a ler razoavelmente, mas não se interessavam pela leitura de nada além dos Sete Mandamentos. Maricota, a cabra, lia um pouco melhor que os cães e costumava ler para os demais, à noite, os pedaços de jornal que achava no lixo. Benjamim sabia ler tão bem quanto os porcos, mas não exercia sua faculdade. Quitéria aprendeu todo o alfabeto, mas não conseguia juntar as letras. Sansão não foi capaz de ir além da letra D [...] Notou-se também que os mais estúpidos, tais como as ovelhas, as galinhas e os patos, eram incapazes de aprender de cor os Sete Mandamentos. Depois de muito pensar, Bola-de-Neve declarou que, na verdade, os Sete Mandamentos podiam ser condensados numa única máxima, que era: "Quatro pernas bom, duas pernas ruim" (ORWELL, 2007, p. 31-32).

Nestes recortes, os sujeitos, resultados da relação com a linguagem e a história, não são totalmente livres, nem totalmente determinados por mecanismos exteriores, mas são constituídos a partir da relação com o outro. Podemos considerar que há um assujeitamento dos animais aos porcos, pois eram submetidos às condições de produção impostas pela ordem superior estabelecida, embora tenham a ilusão de autonomia.

Para Althusser, os indivíduos vivem na ideologia, não havendo, portanto, uma separação entre a existência da ideologia e a interpelação do sujeito por ela, o que ocorre é um movimento de dupla constituição: se o sujeito só se constitui através do assujeitamento é pelo sujeito que a ideologia torna-se possível, já que, ao entendê-la como prática significante, concebe-se a ideologia como a relação entre sujeito, língua e história na produção de sentidos. (ORLANDI, 1999). 


\section{BLOGS E A REVOLUÇÃO DOS “BIXOS”}

Considerando a narrativa: A Revolução dos Bichos, cujo autor, George Orwell, socialista, era crítico mordaz de Stálin devido às suas falsidades e, se lançarmos mão de nosso arquivo ou nossa memória discursiva, podemos considerar que o Velho Major seria Lênin, Bola-de-Neve a Trotski e Napoleão a Stálin.

Navegando na rede encontramos diversos blogs e sites que falam sobre George Orwell e A Revolução dos Bichos.

Os blogs, segundo Komesu (2003), são uma corruptela de Weblog, expressão que pode ser traduzida como "arquivo na rede". É um diário digital na Internet que pode ser visto por qualquer pessoa. Concebido como um espaço em que o escrevente pode expressar o que quiser na atividade da (sua) escrita, com a escolha de imagens e de sons que compõem o todo do texto veiculado pela Internet.

Os blogs possuem características diferentes dos diários tradicionais, pois os antigos diários tradicionais eram privativos, trancados em uma gaveta. Não eram lidos sem a autorização do autor, isso o diferencia do blog, que pode ser acessado e lido por todos. Portanto, diários tradicionais e os blogs são acontecimentos distintos.

Navegando, abrindo páginas e janelas, fizemos "clivagens subterrâneas" nos arquivos que encontrávamos e nos sentíamos verdadeiros internautas. Visitamos o blog Literatura Fantástica (http://literatura.interativo.org/), onde já haviam participado trinta e cinco internautas.

Entre os discursos produzidos pelos internautas, um deles nos chamou mais atenção e o escolhemos para fecharmos o nosso trabalho.

Olá, Adorei a leitura desse livro principalmente pela idéia que tinha com o socialismo de Karl Marx e vejo como é utópico! Ao exemplo do nosso Presidente Lula!!! Que de oprimido passou a ser opressor. Só basta chegarmos ao topo para mudarmos de opinião!

A liderança consome a essência do homem! Quem leu leia mais uma vez!! E quem não leu, de que planeta és??? rsrsrs. LEIAM !!! Cleidy. (LITERATURA..., 2009) 


\section{CONSIDERAÇÕES FINAIS}

Fazendo um paralelo entre texto impresso e texto eletrônico, podemos observar, durante esse trabalho, diversos pontos diferentes. Analisamos a narrativa A Revolução dos Bichos, de George Orwell, 2a reimpressão pela Companhia das Letras, 2007, texto impresso e o texto eletrônico, A Revolução dos Bichos, de George Orwell, no www.comunismo.com.br onde fizemos o download do arquivo PDF.

O livro eletrônico não possui sumário, prefácio ou posfácio. É escrito em fonte menor, sem comentários, sem legendas e a edição não foi revista. Não nos dá liberdade para copiarmos para o Word, mas poderá ser impresso.

Quanto ao livro impresso, podemos folheá-lo e até mudarmos uma página molhando o dedo com saliva, parar a leitura e retomá-la no mesmo ponto que paramos.

\section{REFERÊNCIAS}

KOMESU, F.C. Blogs e as práticas de escrita sobre si na Internet. In: Hipertexto e Gêneros Digitais. Antônio Carlos Xavier (org).

LITERATURA FANTÁSTICA. A revolução dos bichos. Disponível em: http://literatura.interativo.org/livros/2006/05/a-revolucao-dos-bixos. Acesso em 14 jul. 2007.

ORLANDI, E. P. Análise de discurso. Campinas: Pontes, 1999.

ORWELL, G. A Revolução dos bichos. São Paulo: Companhia das Letras, 2007.

PÊCHEUX, M. O discurso: estrutura ou acontecimento. Campinas: Pontes, 1997.

ROMÃO, Lucília Maria Sousa. De areia e de silício: as tramas do discurso no livro eletrônico. Revista de estudos literários: Espéculo, Ano X, n. 31, 2006.

ROMÃO, L.M.S. No país das maravilhas: uma metáfora sobre o dizer na rede. Revista Eletrônica de Divulgação Científica em Língua Portuguesa. Ano 02, n.03, 2005. 
